\title{
Gold in Watchmaking
}

\author{
Lucien F Trueb \\ In der Oberwis 9, CH-8123 Ebmatingen, Switzerland \\ Email:lucien.trueb@bluewin.ch
}

Received: 26 November 1999

The attractive colour of gold, its brightness, durability as well as its tarnish and corrosion resistance made it the choice material for watch cases, from the earliest 'onion' of the 16th century to today's multi-motor quartz wrist chronograph. But the use of gold was never just limited to the case and other visible parts. Fire gilding was used in the earliest watches to protect baseplate, bridges and gears from tarnishing and corrosion. In order to give the watch the highest possible value linked with aesthetics and functionality, most (but not all) watch parts have been made of gold alloys at one time or another or have been gold plated. Gold is purely functional as a brazing compound; it is indispensable for chip bonding, wiring and frequency adjustment in electronic watches.

\section{FROM TOWER CLOCKS TO POCKET WATCHES}

It is impossible to tell when time measurement devices started to take advantage of the decorative and functional properties of gold. The precious metal certainly was used in sundials, clepsydras and hourglasses of different civilizations many centuries before the advent of clocks and watches. We do know that the first tower clocks were built in the last years of the 13th century and very early in the 14th, both in Britain and France. They quickly became status symbols of churches, monasteries and castles throughout Europe all the way to Russia. It was only natural to coat the metal hand(s) and numerals with gold leaf, using the classical gold size as an adhesive, ie a mixture of linseed oil and copals with finely pulverised ochre and litharge. Another possibility was to fire gild them after rubbing with a mercury-gold amalgam; this technology can be traced back to the 4th century BC. Then as now, gold provided long term corrosion protection and superb visibility.

The common view that tower clocks preceded domestic clocks is probably wrong, the development may even have gone the other way. The first reference to domestic timepieces indeed goes back to the end of the 13th century. Be it as it may, wall and table clocks were first commissioned or purchased by members of royal families, the nobility, high ranking clergy and the well-to-do elite. Thus, the clock movement was more often than not hidden in an exquisitely worked and decorated case. All kinds of materials were used, including of course gold. Goldsmiths and jewellers (particularly in Paris and Geneva) were quick to realise that the timepiece was a new product line for them. Only the very rich could afford solid gold, but there was a substantial market for clocks made of gilt bronze, copper, silver or brass. Iron was preferred in Germany, it was copper plated by immersing it into a copper sulfate solution, then fire gilded.

At the beginning the 16th century, spring-driven, truly portable, drum shaped timepieces with just an hour hand appeared almost simultaneously in France, Germany, Great Britain and Northern Italy. Such instruments meant to be carried on the person were called watches. Their mechanisms were similar to that of chamber clocks, but it had taken 50 years to achieve the required miniaturization, which was very labour intensive. Watch movements were expensive, such luxury items thus deserved a gold case. The first gold watches on record were owned by Queen Elizabeth I of England (1533 - 1603); her inventory mentions that they were decorated with rubies, emeralds, pearls, garnets and agates.

From its earliest beginning, watchmaking was both an art and a craft. This applied to the casemakers and to the makers of movements; the latter not only steadily improved timekeeping precision, but also took great care in making their machinery look like works of art. The pursuit of such beauty truly was "l'art pour 
l'art", as the movement normally was invisible to the watch owner. It was not a passing folly: several Swiss and a couple of German firms still (or again) make and successfully sell watches with breathtakingly beautiful (and very expensive) mechanical movements. In former days, only the watchmaker would see them; nowadays such luxury watches are provided with a sapphire glass back, so the owner can enjoy the beauty he bought. This beauty is reduced to a network of golden lace supporting barrel, gear train and regulating organs when the movement is 'skeletonized'. No dial is provided in such watches; their movement is sandwiched between two sapphire crystals in order to make them as transparent and 'airy' as possible.

Aside from the above exceptions, the watch movement is usually hidden from view; only the case, the dial and the other external parts are fully exposed to view. Early casemakers had to be superb artists, as their clients belonged to the aristocracy and the very wealthy. Some of the greatest works of art 'en miniature' were created for them, particularly in Paris and Geneva - invariably using gold. The precious metal was not only exquisitely fashioned, engraved and patterned, it also served as a base for diamonds, pearls and coloured precious stones as well as for miniature enamel painting. 'Champlevé' enamel was always done in gold, so was cloisonné, the motifs being drawn with gold wire glued to a gold substrate; firing the enamel also welded the gold.

\section{ART AND TECHNOLOGY}

The beauty of the (mostly French and British) watches of the 16th and 17th century has never been matched. They were equipped with high quality movements on both sides of the Channel, but they lacked ruggedness and durability in France. Miniature painting with metal oxides on a white enamel background fired on gold became a speciality of the craftsmen in Blois and Paris. They decorated the entire case and the dial in this manner, the cover inside and outside, leaving only gold circles and fine gold patterns at the periphery. British watchmakers on the other hand fitted the best high precision movements of the time into wonderfully decorated cases using rock crystal, gold, silver, precious stones and enamel during the Stuart period; some of those cases were imported from France. When luxury fell out of fashion under Cromwell in the middle of the 17th century, the very stark, oval shaped 'Puritan watches' appeared; their case was usually made of polished brass, but plain polished gold was used occasionally.
With Huygen's invention of the balance wheel and hairspring in 1675, the precision of watches gained an order of magnitude. They now became instruments, not just beautiful pieces of jewellery giving the approximate time. Gold - engraved and patterned regained its place in the case; if the latter was made of brass, it was often covered with black leather or sharkskin, which itself was patterned with gold (or silver) rivets. The movement, now a reason for pride and usually made of gilt brass, was provided with a circular, large diameter balance cock exquisitely decorated with carved and engraved floral and animal motifs; it entirely covered the balance wheel.

Inevitably, this led to excesses such as enamelled medallions decorated with precious stones serving as balance cock, engraved bottom plates and bridges, shaped pillars etc. Miniature enamel painting continued though and still flourished until the end of the 19th century, both in Paris and Geneva. The same applies to unpainted, translucent enamel which was applied to gold watch cases with guilloché work; this technology was particularly appreciated in Great Britain in the early 19th century. An earlier British speciality in the middle of the 18th century was gold relief (achieved by the repoussé technique) with mostly mythological scenes on both sides of the case.

The 'problem' of the French and British watchmakers was that they catered for the rich: they produced individually crafted masterpieces in small quantities at very high prices. The watchmakers in the

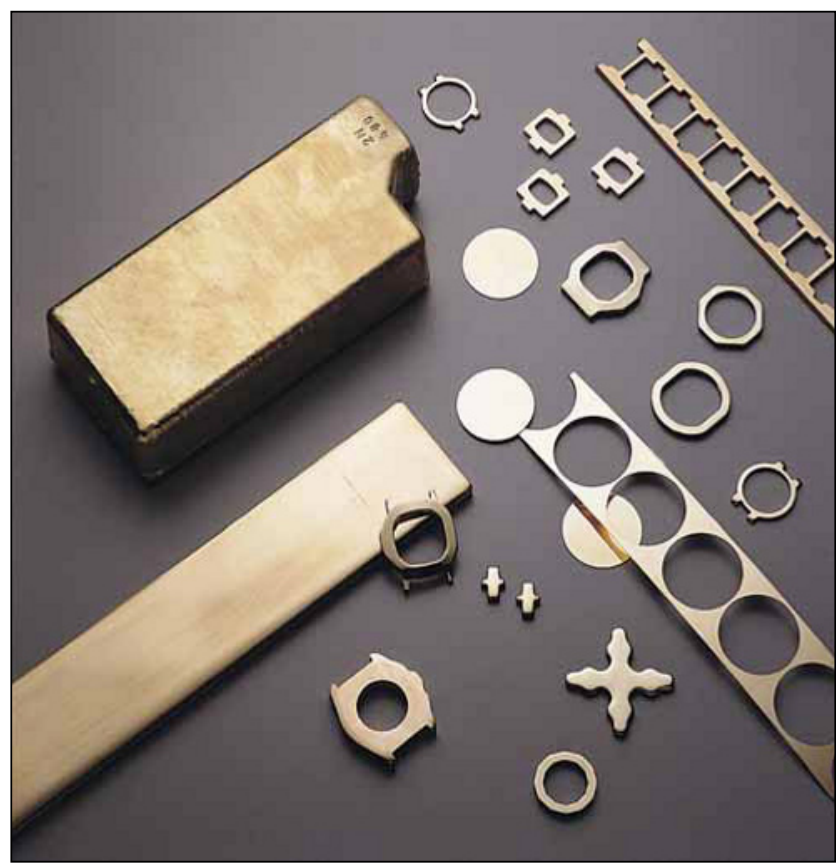

Figure 1 Gold blanks for cases and case bottoms. (Precinox, La Chaux-de-Fonds) 


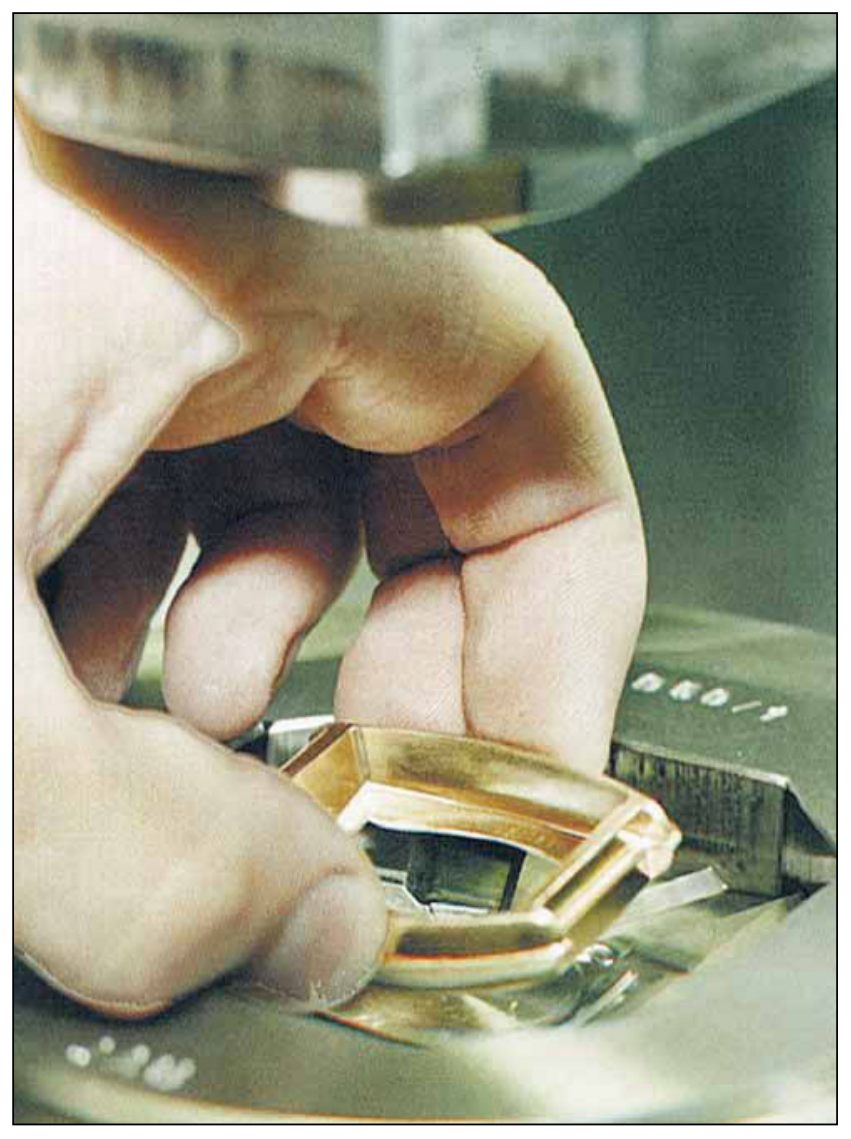

Figure 2 Cold impact die forging of a tonneau shaped gold case. (Varin Etampage, Delémont)

Swiss Jura mountains and (to a lesser extent) in Geneva, applied the principles of mass production and extreme division of labour. This allowed the production of plain but functional timepieces at reasonable prices, which created a growing mass market. The Swiss thus became aggressive competitors of the British and French watch industries in the 18th century. First they undersold everybody with silver watches for 20 francs and gold watches for 120 francs. Then they became technically innovative, as their technology evolved from the verge to the cylinder and ultimately to the anchor escapement.

As the fusée became unnecessary due to advances in spring steel and spring technology, the watch could be made significantly thinner and smaller, which meant less gold for the case and still lower prices. Thus, the 'onion' of 1700 with a thickness of nearly 40 $\mathrm{mm}$ and a diameter of $60 \mathrm{~mm}$ gave way to the $50 \mathrm{~mm}$ 'Lépines' of 1780 , which were only $15 \mathrm{~mm}$ thick. Another half century later, the craftsmen in the Vallée de Joux were making movements that were just slightly over $1 \mathrm{~mm}$ thick, which they fitted into $3 \mathrm{~mm}$ thick watches. In order to beat their competitors, the Swiss casemakers learned to make very thin gold cases which were rather weak, as they consisted of $0.15 \mathrm{~mm}$ gold plate and weighed only 20 to 30 grams. Thus, around 1850, the gold in a British watch was worth 7 pounds sterling, that in a Swiss watch only 2. Of course, the latter was much cheaper, and it still was a gold watch, albeit quite delicate. This tradition of making gold watches with an absolute minimum of precious metal continued with the advent of the wristwatch; old timers in La Chaux-de-Fonds vividly remember cases for small ladies' watches with a $63 / 4$ line movement which weighed all of 1.6 grams.

\section{THE GOLD WATCH INDUSTRY}

In the latter part of the 19th and in the 20th century, the Swiss watch industry expanded enormously and became a dominating force world-wide. It also survived many crises; the worst one in the early eighties of the 20th century was due to the 'quartz revolution' which swept away the entire branch of cheap mechanical watches. Some 60,000 jobs were lost in the process, which nearly corresponded to two thirds of the entire industry's workforce. The well managed manufacturers of high end watches hardly noticed the crisis: there always is a class of very wealthy people who will buy the ultimate in luxury, quality and beauty regardless of price.

Today, the Swiss watch industry keeps growing nicely in terms of sales even though the number of watches sold per year hardly changes at all. This means that the price tags are getting bigger, which can be easily achieved by using more gold! This explains in part why more than $90 \%$ of the world's gold watches are made in Switzerland. Some 450,000 pieces per year bear the Swiss hallmark, more than a fifth of them are imported, mostly from Italy. The vast majority of gold watch cases are $18 \mathrm{ct}$; only Britain, part of the British Commonwealth, the US and some Scandinavian countries accept $14 \mathrm{ct}$ gold watches and import 16000 of them per year, Japan makes even 9 ct cases for those markets. The spread in terms of weight is very wide: 8 grams suffice for a small lady's watch, but about $65 \%$ of the Swiss gold watches bear the Rolex crown on the dial. Rolex cases weigh $40 \mathrm{~g}$ each, which has a very significant impact on the statistics.

Switzerland does not by any means have a total monopoly in the gold watch business. The three large Japanese manufacturers of analogue watches (Citizen, Orient and Seiko) together produce some 25,000 gold case watches mostly for the domestic market. Finally, 


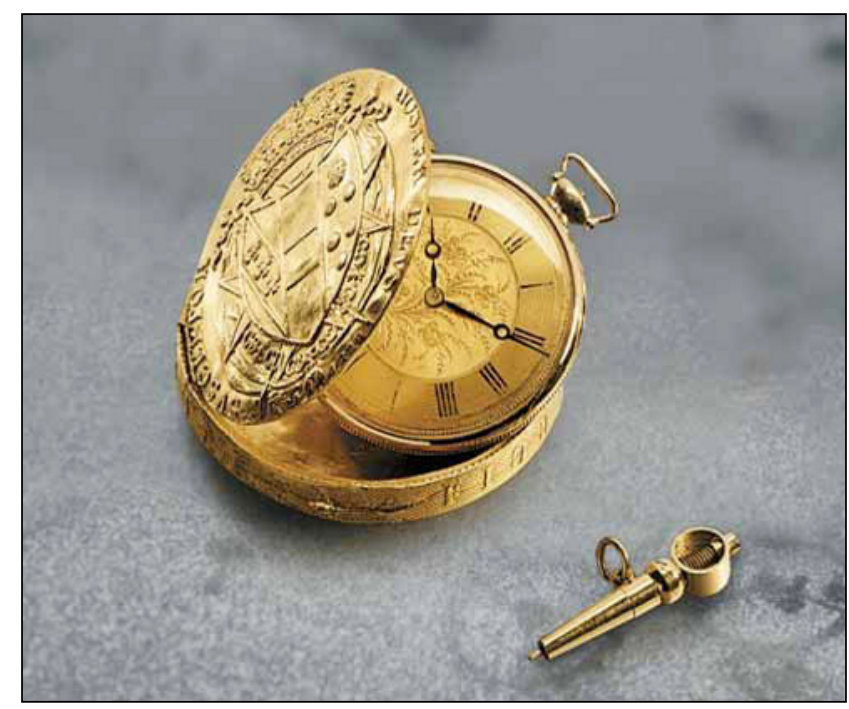

Figure 3 The oldest coin watch on record: Florentine double ducat hollowed out to fit a small, 1820 Lépine gold watch. (Girard Perregaux Museum, La Chaux-de-Fonds)

Museum, La Chaux-de-Fonds the Indian watch manufacturer Titan in Bangalore (a Tata Group company) makes some 8,000 to 10,000 watches per year with an $18 \mathrm{ct}$ gold case weighing 40 to $60 \mathrm{~g}$ in the men's sizes. They are sold on the domestic and export markets under the 'Tanishq' brand. All in all, gold watches world-wide absorb anywhere between 8 and 12 metric tonnes of fine gold per year, depending on whose statistics (or lack of them) you believe. About 15 Swiss companies produce gold watch cases, several of them also specialize in gold watch bands, which weigh between 20 and $100 \mathrm{~g}$ each. The quantity of gold used for the latter purpose can only be roughly guessed at 10 to 13 tonnes; no quantitative information is available from the manufacturers, the biggest one again being Rolex.

The buyer of an $18 \mathrm{ct}$ yellow gold watch has a choice of half a dozen colours plus another good half dozen for white gold. There are distinct national preferences: German $18 \mathrm{ct}$ gold is bright yellow (' $2 \mathrm{~N}$ ') and contains $10 \%$ copper and $15 \%$ silver, while the Swiss variety is a darker yellow (' $3 \mathrm{~N}$ ') and contains $12 \%$ copper and $13 \%$ silver. The latter colour is preferred in combination with steel for 'bicolore' cases and bracelets. Rosé gold (' $4 \mathrm{~N}$ ') contains 16\% copper and $9 \%$ silver, while red gold (' $5 \mathrm{~N}$ ') contains $21 \%$ copper and only $4 \%$ silver. Watchcases are mostly made of the $2 \mathrm{~N}$ type, as $95 \%$ of Swiss made gold watches are exported. However, certain manufacturers insist on rosé or red gold as their 'trademark' ( $4 \mathrm{~N}$ and $5 \mathrm{~N}$ colours). The $2 \mathrm{~N}$ and $3 \mathrm{~N}$ type alloys are available in fine grained varieties specifically for watchcases, as they are easier to polish to a high gloss; traces of iridium are added for grain growth inhibition.

As far as white gold is concerned, the $18 \mathrm{ct}$ alloy with $16 \%$ palladium and $9 \%$ silver was quite widespread in the days of cheap palladium. Nickel white gold has totally fallen out of favour because of its allergenic potential. The law requires that no more than 0.5 micrograms of nickel are given off per square centimetre per week; this is easily achieved, but nobody wants to take a chance. White gold is presently very much in fashion, but it is expensive, as the palladium price has enormously increased in the past few years. This is mostly due to the uncertain supply situation (70\% of that metal comes from Russia) and steadily increasing demand for automotive catalytic converters. White gold alloys with $12.5 \%$ or just $10 \%$ palladium (the latter need manganese or iron for strengthening) have been developed to save palladium. Some of the new white gold alloys can be hardened by heat treating, grain growth being inhibited with iridium. Other low palladium white gold alloys which do not need to be rhodium plated were recently introduced.

The alloys Gold 990 (23.76 ct) with 1\% titanium and gold 986 (23.66 ct) with $1.4 \%$ titanium plus copper, never made the breakthrough that had been hoped for, despite their good mechanical properties and machinability. In the age-hardened condition, they are similar to $18 \mathrm{ct}$ alloys. For one thing, gold 990 and 986 are about $30 \%$ more expensive than $18 \mathrm{ct}$ gold, as they contain a lot more precious metal. Also, one must be aware of the fact that any price differential at the level of the case is multiplied eightfold by the time the complete watch makes it into the retail store display. Furthermore, recycling this type of alloy poses problems, both technical and economical, as gold refiners are not used to dealing with titanium. Only the Japanese owned American-Swiss Waltham Watch Company tried gold 990 in watch cases, but only with moderate success; there were no followers.

\section{SOLID GOLD WATCH PARTS}

Gold watches can be immediately recognised if they are turned around: the back of the case must be made of gold, while gold plated watches use a steel back. Professional burglars know that: they wouldn't touch gold plate, for which there is no second hand market. Solid gold may be used in seven major parts of a modern wrist watch: case (including back and bezel), dial, hands, crown, pushers, bracelet and clasp (for leather straps). This applies to both mechanical and electronic watches. 


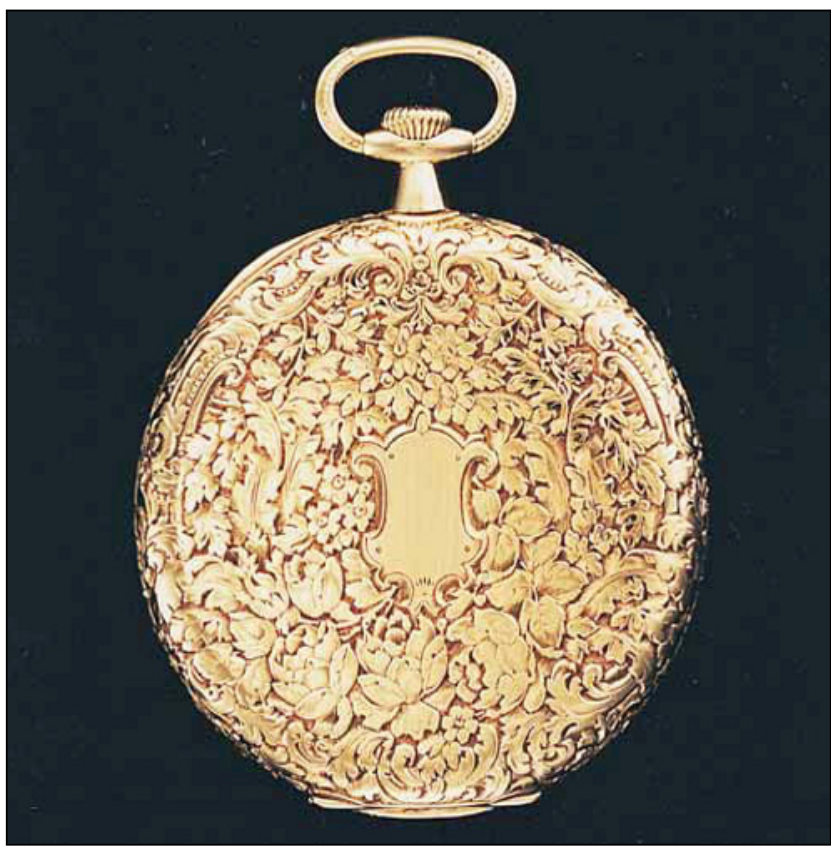

Figure 4 Albert Einstein's Patek Philippe ultra-slim pocket watch with gold case and engraved back, which he bought in 1915 after his move from Zurich to Berlin. (Patek Philippe Collection, Geneva)

\section{Cases}

The invention of the wristwatch is claimed by several companies, but it is likely that Girard-Perregaux in La Chaux-de-Fonds really were first. The German Emperor commissioned them as early as 1879 to fabricate a series of small watches equipped with a leather strap, as they were meant to be worn at the wrist by Naval officers. These watches were used as deck watches for navigating on the high seas and had to be corrosion resistant: for this reason, the cases were made of 14 ct gold. Apparently, the very first wrist watches were gold watches; this seems to be rather extravagant for armed forces issue, but stainless steel did not exist yet and brass just would not do.

The Swiss watch case manufacturers buy most of their raw gold parts from two suppliers: Precinox in La Chaux-de-Fonds and Metalor in Neuchâtel. Both of those companies do their own chemical and electrochemical refining to 99.99+ fine gold, whether they start from bullion or gold scrap, in order to eliminate impurities, particularly the hard osmium / iridium and/or ruthenium based particles, which make smooth polishing impossible. This is followed by vacuum melting and alloying under vacuum. Precinox alone have some 20 alloys in the $18 \mathrm{ct}$ class for applications in jewellery and watchmaking. Ingots are rolled to flat strips or bars, 8 - 10 passes are needed to achieve $75 \%$ reduction, then the material is annealed to eliminate work hardening and rolling continues following the same procedure until the desired plate thickness is reached. Bars may have a rather complicated cross section and are either used as such, drawn to wire ( 0.8 to $8 \mathrm{~mm}$ diameter) or processed to tubing: such material is needed for making gold bracelet links, crowns, screws and other small parts.

Gold strips a few millimeters thick are the raw material for the fabrication of watch cases. Flat, ring shaped parts roughly approximating the desired shape, including the horns for attaching the strap or bracelet, are cut out of the strips by blanking. This is as far as the gold supplier normally goes; the next step is impression die cold forging, using hardened, $1 \%$ carbon, manganese steel tools to give them the final outer shape, which is mostly done by highly specialised companies. Those tools are made by electro discharge machining (EDM), using hand made or NC milled copper prototypes of the future case as electrodes. Impression die forging is based on plastic deformation; it is an extremely demanding job which is mastered only by highly specialised companies, Varin-Etampage in Delémont being one of the major ones.

The forging tools themselves and their inserts must be changed several times in the course of operations, as anywhere between 5 passes (for very simple shapes) up to 40 passes (for the most complicated cases) at pressures between 80 and 120 tonnes are needed for achieving the final shape. After every pass, the $18 \mathrm{ct}$ gold pieces must be annealed at 640 to $650{ }^{\circ} \mathrm{C}$ in order to soften them. Material is squeezed out of the edges (inside and out) at each pass in the press; this flash has

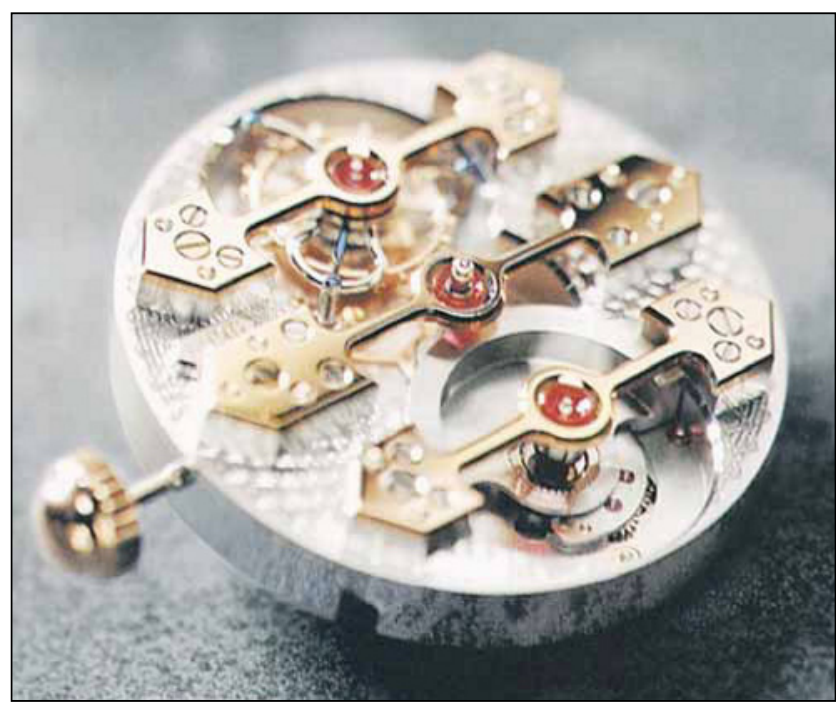

Figure 5 "Tourbillon sous Trois Ponts d'Or" with three symmetrical $18 \mathrm{ct}$ red gold bridges. (Girard Perregaux) 


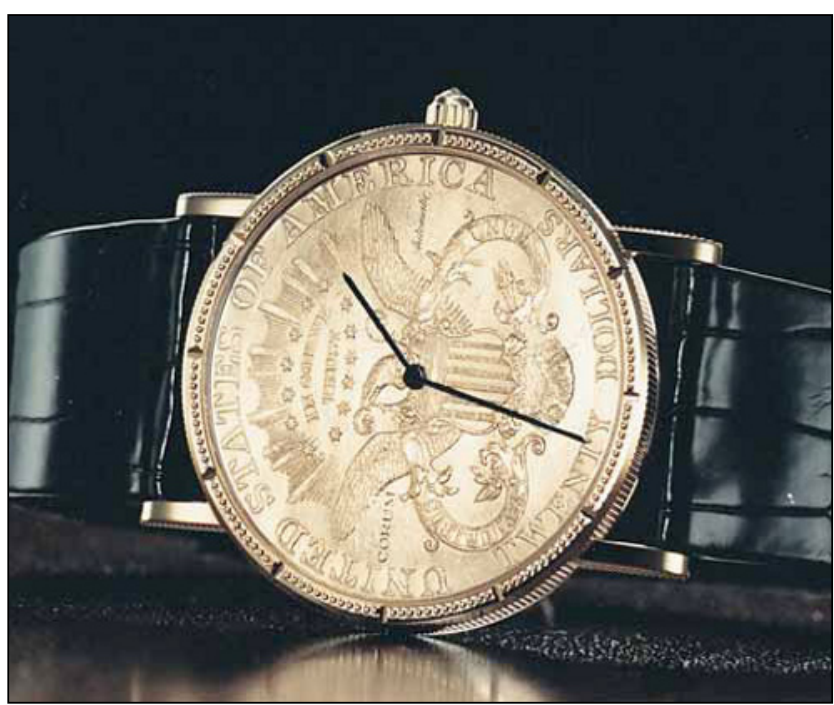

Figure 6 The 'Monnaie' coin watch, based on an American Double Eagle. (Corum, La Chaux-de-Fonds)

to be trimmed off several times in the course of forging operations. A precision of $+20-0$ micrometers is routinely achieved. Even though the sets of forging tools are designed by computer, a tremendous amount of practical experience as to the flow characteristics of gold under high pressure is stored in the programs. Impression die forging is particularly difficult with the asymmetric cases coming into fashion. It is advantageous to polish the cases after each 4 or 5 passes in the press.

Forging operations involve very expensive tooling but give the case manufacturer nearly unlimited possibilities in terms of non-round shapes. Sharp inner angles (which occur in square, rectangular and tonneau cases) and deep grooves cannot be made by milling at all. Furthermore, a forged piece has a nearperfect finish and can be polished or brushed without problems. Forging closes any pore and microcrack near the surface, which is not the case with fully milled objects. But innovations in terms of shape are not possible before the forging tools have been amortised. NC machines are much more flexible in this respect; they are preferred for the fabrication of simple, round cases, on which the horns are brazed. The same applies for large, ring-shaped bezels, which are often provided with a steel insert on the side facing the case in order to lighten them and save gold. The flat or slightly curved case bottom as well as the bezel may be either blanked and forged, or milled from a solid disk. The bottom is usually standardized in terms of size and thread, while the outer shape of case and bezel are often modified for the sake of innovation.
The case manufacturers machine the inner recesses for bezel, crystal, crown, movement and bottom, which involves milling, drilling, lathe cutting and tapping. Polishing is done by hand with mildly abrasive pastes containing colloidal cerium oxide or aluminium oxide particles. This operation requires a tremendous amount of know-how, skill and experience; robotizing it is not economical, due to the small series. A perfect mirror finish is obtained by diamond burnishing. The case manufacturer completely assembles the case (including the crystal) and delivers it to the watch manufacturer, where the pre-assembled movement with dial, hands and crown is fitted. Finally, the strap or bracelet is attached.

In contrast with the rest of the Swiss watch industry, the Swatch Group controls two fully integrated gold watch case and bracelet fabrication facilities: Favre-Perret in La Chaux-de-Fonds and Lascor in Sesto Calende at the South end of Lago Maggiore in Northern Italy. Both companies also make cases for high end watch manufacturers not belonging to the Swatch Group. At the Lascor plant, fabrication starts with 999.9 bank bullion and internally recycled fine gold to make the required standard grade alloys $(2 \mathrm{~N}$ to $5 \mathrm{~N} 18 \mathrm{ct}$ gold alloys plus nickel-free palladium white gold not needing rhodium plating), which are processed to strip or bar stock by continuous casting. Cases are made from stamped, forged, machined, diamond burnished and polished gold strip. The bars serve as raw material for bracelet links, which are made from forged pieces or wire drawn tube sections. The nearly complete cases and bracelets are then brought across the border to Switzerland where the composition is checked and the Swiss hallmark is stamped on. Then the cases are brought back to Sesto Calende for final polishing and assembly. Recycling and chemical refining of the gold are also done in house by Lascor.

Aside from conventional watch cases, Lascor manufacture thin-walled, so-called 'monocoque' cases, mainly for the Tissot brand. Such watches are made for the company incentive market in the Scandinavian countries. The cases contain only $9.5 \mathrm{~g}$ gold for an 18 ct men's watch with a diameter of 32 to $33 \mathrm{~mm}$; they are cup shaped with integrated bottom, the movement is mounted from the top and must be removed in order to exchange the battery.

The casemaking technology used by the Geneva watch manufacturer Patek Philippe lies halfway between 'big industry' and handicraft. Patek is a true manufacturer with a fully integrated production of some 25,000 luxury watches per year, $90 \%$ of which 
have a gold case. There is one stainless steel model family (for ladies) and small series of steel-gold and platinum watches in the collection. Otherwise, the firm identifies itself with gold and shows a definite preference for pink $(4 \mathrm{~N})$ and red $(5 \mathrm{~N}) 18 \mathrm{ct}$ gold. Most watch models are available in three gold colours, in addition to palladium white gold.

As the series are too small for in-house gold refining and alloying facilities, Patek Philippe buy pre-shaped case rings (which always include horns for strap attachment), case bottoms and bezels as well as wire and forged links for metal bracelets from specialised suppliers. Thus, cold forged and even lathe cut pieces are received; they are finished at the Patek Philippe plant by cold forging using the final 5 to 8 dies followed by $\mathrm{NC}$ milling, cutting and polishing. The idea is to buy as close as possible to the final shape and generate only an absolute minimum of scrap. Machining of the precious metal is done with dedicated machinery, even white and yellow gold scrap are separated at the source. Gold dust and filings are collected everywhere in the plant (partly by permanently installed vacuum lines to the work benches), melted and returned to the suppliers for refining and re-alloying.

Patek Philippe is the last independent Geneva watch manufacturer uniting all of the classical 'professions' of watchmaking under one roof and even training apprentices in all of them: designer, movement maker, goldsmith, jeweller, engraver, miniature enamel painter and chain maker. Thus, cases, bezels and bracelets are decorated in Patek's own workshops; this includes setting diamonds and coloured stones. Even the ancient art of engine-turning ('guillochage') has been revived by revamping a vintage 1913 machine and having a long retired guillochage master train a new generation of operators. Engine turning is used mostly for patterning the back and/or cover of pocket watches. This pattern is recorded on a master plate and copied in reduced size by mechanically scanning the pattern, while the tool end with a hard metal tip hammers on the gold. Miniature enamel painting of cases is done to order, the theme is usually a classical painting which is copied "en miniature" on a matte gold background. The same applies to engraving of geometrical and floral patterns, which is entirely done by hand using simple steel tools. Very deep patterns are obtained by chiselling, which actually involves the use of cold chisels and a mallet. The wave-shaped 'Geneva stripes' are applied to the movement parts with a rotating boxwood tool.

While gold cases for many famous Swiss watch brands are made by the thousands if not ten thousands per year (add another zero for Rolex), a few small manufacturers are doing quite well fabricating one-of-a kind watches for wealthy collectors as well as small series of very special (and extremely expensive) pocket and wrist watches with all kinds of complications. Thus, Michel Parmigiani in Fleurier (whose company shares are partly owned by the Sandoz Foundation of Basel chemistry fame), makes a grand total of 800 watches per year with some 40 employees. The cases for those exquisite watches are either yellow, pink or white gold, with platinum thrown in for good measure.

Most of Parmigianis cases are individually made by a superb craftsman and artist by the name of Bruno Affolter in La Chaux-de-Fonds who just recently added a NC milling machine to his inventory of classical high precision machinery, with which every piece used to be hand crafted. Affolter literally lives in symbiosis with his customers who just give him the dimensions of the movement they want to be cased with the instruction 'Do it my style'. The largest order he ever received was for 50 identical pieces, but the challenge he particularly enjoys is the individual, very complicated collector's piece, usually a pocket watch with repeater, perpetual calendar, 'grande sonnerie' or chronograph functions. Waterproof gold cases for wristwatch repeaters or Westminster chime watches are another speciality of the house. Among his customers one finds high prestige names such as Breguet, Girard-Perregaux,

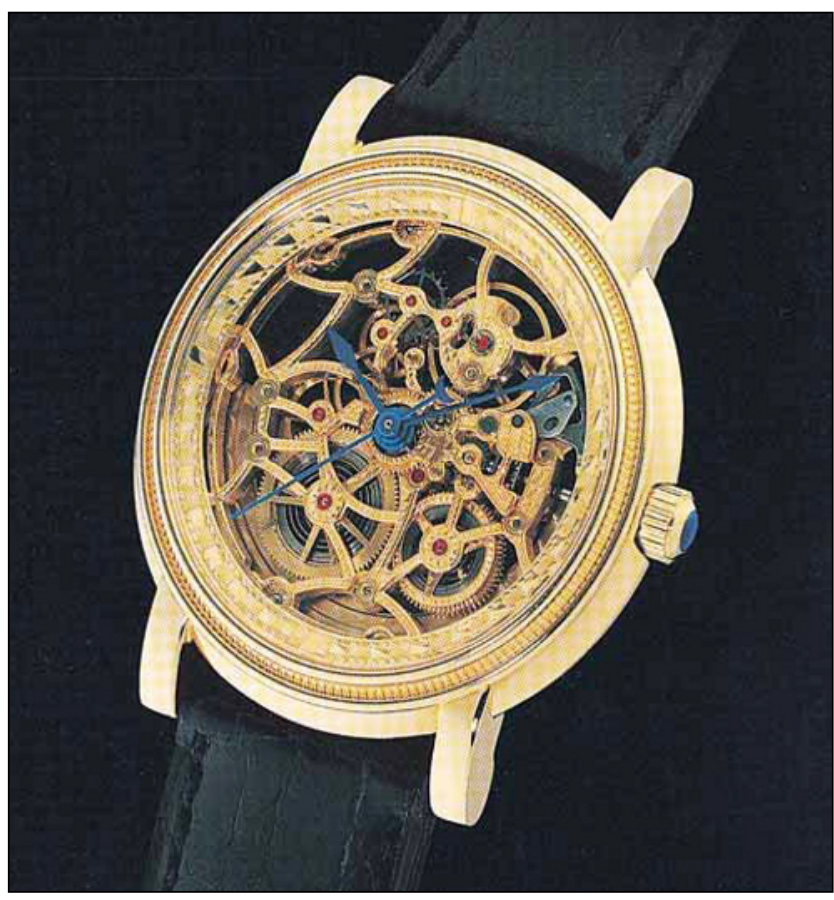

Figure 7 Automatic skeleton wrist-watch with gold-plated movement and $18 \mathrm{ct}$ yellow gold case with four quadrants engraving. (Parmigiani, Fleurier) 


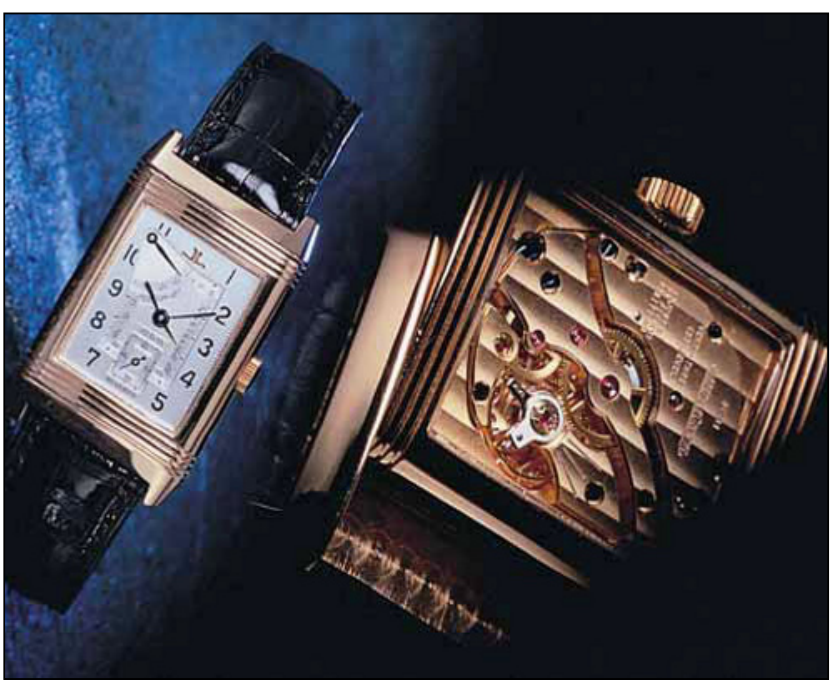

Figure 8 Reverso '60'me' with pink gold case and $14 \mathrm{ct}$ baseplate and bars. (Jaeger-LeCoultre, Le Sentier)

Kelek, Ulysse-Nardin and Vacheron \& Constantin. Parmigiani delivers the complete case, polished and decorated including crystal, seals and crown.

A pocket watch case starts with a blanked, ringshaped central part which is machined to the desired shape by copying it from a brass model - or feeding the appropriate software into the NC machine's memory. Back, inner cover and bezel are made of cold forged or embossed gold plate; the hinges are machined and brazed in place. Only very thin gold plate can be deformed by the repoussé technique, using appropriately shaped wooden tools; this technology is hardly used any more, as gold pocket watches are luxury items which are expected to contain a lot of gold. A Savonnette case made of 0.7 to $0.8 \mathrm{~mm}$ thick $18 \mathrm{ct}$ gold plate for a complicated movement weighs between 180 and $200 \mathrm{~g}(300 \mathrm{~g}$ being the extreme value), while an open face Lépine case for a "Grande complication" weighs 150 g. On the other hand, only $75 \mathrm{~g}$ of $18 \mathrm{ct}$ gold are needed for an extra flat pocket watch case.

\section{Watch Hands}

An analogue watch has at least a minute hand and an hour hand; a small or large (central) second hand is a very frequent feature, particularly in men's watches. Thus, watch hands are usually sold by pairs or triplets, bearing in mind that a chronograph can have up to seven hands while complicated watches such as a "Grande complication" can have many more. High lustre gold hands look very attractive, but in most cases, gold plated brass is acceptable. Solid gold hands are only found in high prestige watch brands; Rolex,

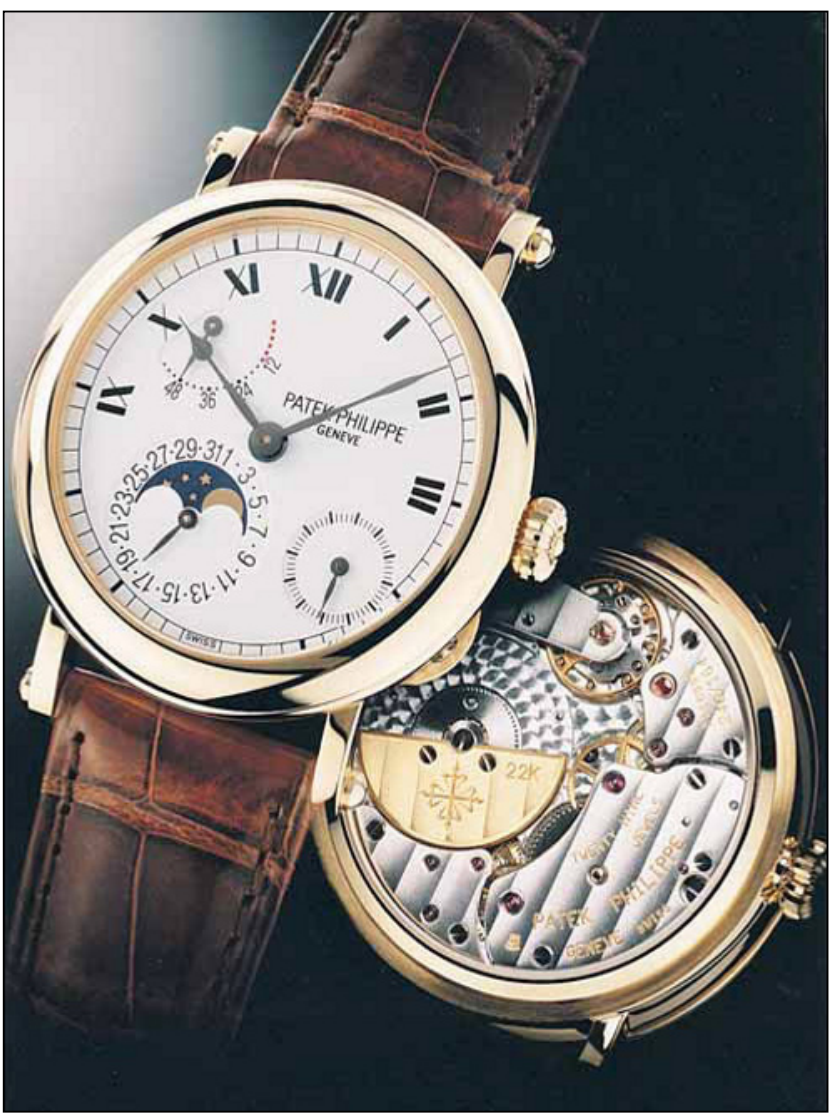

Figure 9 Automatic wristwatch with 18 ct yellow gold case and 22 ct gold minirotor. Gold-plated gears and balance wheel. (Patek Philippe, Geneva)

the only luxury watch made in huge series, absorbs the lion's share with several hundred thousand sets of gold hands per year.

The fabrication procedure of solid gold watch hands is practically identical to that of brass or gold plated brass hands. However, the series are much smaller; ten sets of a given style is not an unusual order, 100 to 150 sets is considered as a large order, unless you make watch hands for Rolex. Only parts of the automated processing equipment for punching, patterning, embossing and cutting can be used. This is one of the reasons why gold watch hands are so very expensive: no economy of scale, craftsmanship instead of automation. Add to that the often very exclusive and complicated shapes required for the luxury watch trade: expensive tooling is then needed for very small series. Diamond burnishing is used for very high gloss gold hands. The ultimate, one-of-akind luxury watch is equipped with individually hand crafted gold hands; they look as perfect as if they had been cut by an NC machine, but just a set of files was needed to fabricate them - aside from a tremendously skilled pair of hands. 


\section{Dials}

The watchface or dial is seldom made of solid gold. Shiny gold hands on a matte, finely engraved or patterned gold watchface do not provide the world's best contrast, but they are tremendously elegant, particularly if both the hour-indexes and the hands are diamond burnished. Gold indexes (possibly in another colour than the dial), are machined individually; they are provided with tiny feet which fit into $0.2 \mathrm{~mm}$ diameter holes drilled in the dial; they are set by hand and riveted in place. Since the watch dial is not subjected to any appreciable mechanical stress, brittle blue and violet gold compositions (the intermetallic compound $\mathrm{AuAl}_{2}$ ) are occasionally used for this part, notably by the Geneva manufacturer Patek Philippe.

The dial is the largest flat surface facing the watch owner; for this reason, nearly absolute perfection is mandatory. Any kind of finish has been used for watch dials: polished, matte, brushed, shot-peened, patterned, guilloché, engraved, enamel painted, foil gilded. Scales, numerals, brandnames, logos and any kind of pattern can be obtained by embossing and even machining, but transfer stamping is not unusual even on gold dials. The small second hand and chronograph counters often run in a circular, recessed part of the dial, the angled edge of which is given a high gloss by diamond burnishing. Very special dials

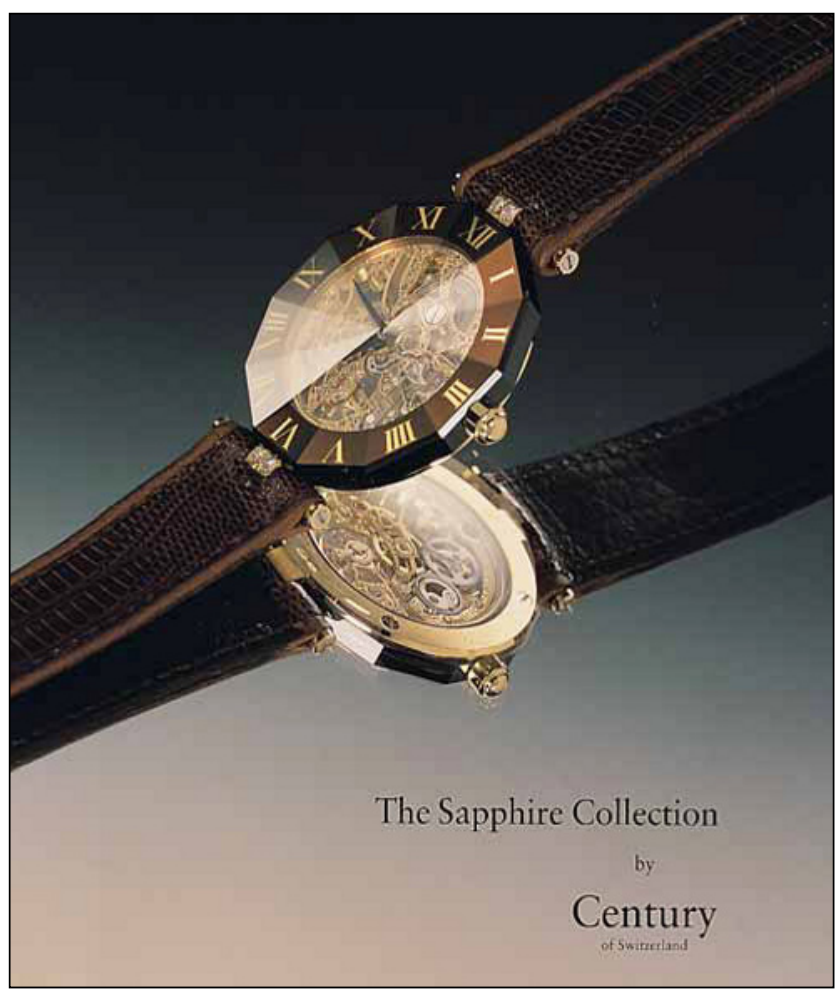

Figure 10 Skeleton 18 ct movement by Frédéric Piguet in a Sapphire watch case. (Century Time Gems, Nidau) are decorated by the cloisonné enamel technique on gold foils. The most expensive dials are of course covered with diamonds ('pavé); the support consists of white gold which is drilled so the stones can be set, the alternative process being electroforming the fully pierced dial without machining.

As mentioned above, only luxury watches of the highest standing are provided with a solid gold dial. Such dials may not look like gold at all, as they are often rhodium plated or even titanium coated by PVD. Yet, the customer knows that he is looking at an exquisitely fashioned gold disk, the thickness of which ranges from 0.3 to $1 \mathrm{~mm}$. It goes without saying that the time spent with fashioning and decorating such a dial is worth much more than the precious metal it contains. Besides, gold takes the absolute best guilloché or engraved finish. Solid gold is the preferred substrate for onyx, lapis lazuli or mother of pearl dials. It goes without saying that the two small disks representing the moon in luxury moonphase indicators are also solid gold.

In watches with less than stratospheric prices, gold plated brass is almost the rule when a gold coloured dial is called for. The fabrication process is practically the same, regardless of the alloy: one starts with strips $43 \mathrm{~mm}$ wide and 0.3 to $0.4 \mathrm{~mm}$ thick, which are provided with guiding holes on both sides. They allow a precise positioning for the opening the central hole, the window(s) for the day and date indications and other holes (small second hand, chronograph counters, etc.) by punching. The holes for the index feet are drilled, due to their small diameter. Then, the future dial is cut out of the strip by blanking between the appropriate punch and die.

The rough disks are ground to perfect planarity and polished. Recesses are milled in, patterns may be applied before the dials are run through a series of cleaning and washing baths (only aqueous detergent solutions and pure alcohol are permitted nowadays). Rotating copper brushes are used for brushing. Gold dials may be given a flash of 24 ct gold by electroplating to adjust the colour; the same applies to brass dials which need only a 0.3 micron gold coating as there is absolutely no wear on this part of the watch.

Galvanoformed dials are a speciality of the Blösch Company in Grenchen, Switzerland: this technology is used when complicated patterns are needed. One starts with a mould bearing the desired pattern, from which any desired number of polystyrene replicas can be made. Vacuum evaporation of silver makes them electrically conductive. Copper is then electroplated to the desired thickness ( 0.3 to $1 \mathrm{~mm}$ ) and ground to 


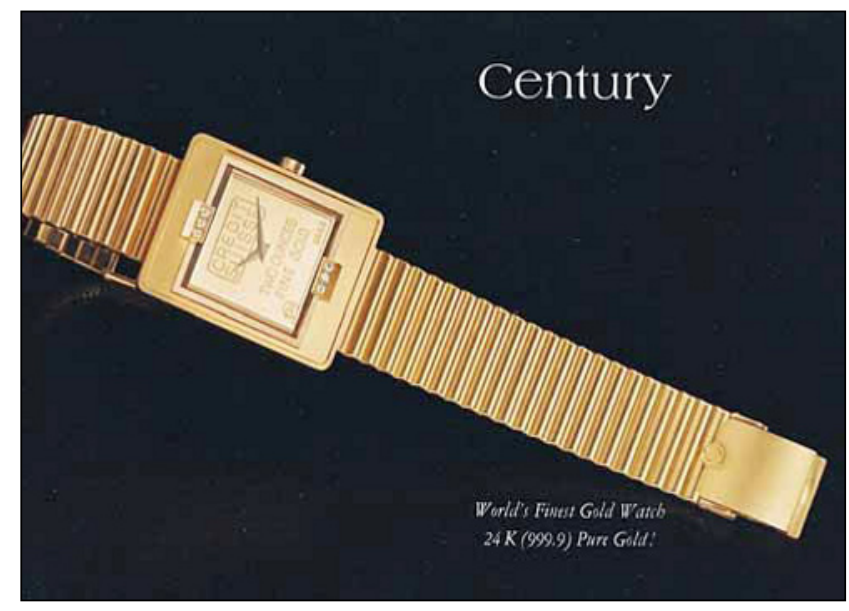

Figure 11 A two ounce fine gold bank bullion bar, hollowed out to serve as a watchcase. (Century Time Gems, Nidau)

perfect flatness. Finally, the plastic substrate is removed with a solvent: one is left with a silver plated copper dial, which can be galvanically gold plated, photolithographically masked and further patterned (eg with black nickel) for multicolour dials.

\section{Crowns and Pushers}

Quartz and automatic watches do not of course need to be wound, but they have to be set and the date must be adjusted once in a while (unless you have a perpetual calendar). The crown is thus functionally indispensable in any kind of watch, but it also has an important aesthetic function. Just changing the style of the crown can make the watch look quite different. The same applies for chronograph pushers and accessory pushers, but the styling latitude is not very wide with those elements: they can either be round or flat. In truly waterproof watches, both crown and pushers are of the screw-down type. One of the main, fully integrated manufacturers of steel, titanium and gold crowns in Switzerland is Meco in Grenchen. It belongs to the Swatch Group, but sells about $40 \%$ of its production to manufacturers of luxury watches outside the group.

Gold crowns and pushers are a must for solid gold watches; they cost up to 4 to 10 US $\$$ a piece even though they weigh only 0.25 to $0.5 \mathrm{~g}$. They are made from round or flattened $18 \mathrm{ct}$ rods, respectively, which are cut in sections and given their outer shape (and logo) by impression die cold forging, with usually just two passes followed by washing, polishing, annealing and some lathe cutting. Remarkably, the volume of the raw gold cylinder is calculated so accurately that absolutely no flash is formed during the forging operations. No polishing is required after cold forging either, as the dies are made to exacting specifications; crowns requiring a mirror-type finish are diamond burnished. Watches with gold plated cases are fitted with electroplated stainless steel crowns, which are fabricated just like solid gold crowns.

Simple crowns which are just tapped so they can be screwed on the winding stem are (almost) a thing of the past. Nowadays, even inexpensive watches are at least water protected, which means that the winding stem passes through a short piece of pipe ('tube') brazed to the case or given a press fit. For water protection, the crown is hollowed out and the inner wall is grooved on a high precision lathe. It can then be fitted with two tiny neoprene O-ring gaskets which slide on the tube wall when the crown is pulled.

Truly waterproof watches are equipped with screwdown crown(s) and chronograph pushers. Most owners of such watches do not realise that their watch crown is not just tapped, but is hollowed out extensively in order to make room for a sophisticated mechanism consisting of at least seven and up to a dozen tiny, high precision, moving metal parts which are made by milling, drilling, tapping and turning on automatic NC machines. They must be assembled manually and fitted into the crown with several gaskets by personnel with the skill of a watchmaker. They have the function of a position selective clutch which disengages the winding stem from the crown in the lowest position, so the crown can be freely screwed onto the tube. At the same time, unscrewing the winding stem from the movement must be avoided. Waterproofing is maintained regardless of the position of the winding stem.

\section{Gold Movement Parts}

Gold may be used for most parts of a mechanical watch movement, but gold plated brass looks just the same and is much cheaper. Yet, automatic (ie self winding) movements for high end watches are provided with a gold rotor. In order to achieve the highest possible density, a $22 \mathrm{ct}$ alloy is often chosen for this part. Mechanical movements of the luxury class sport gold "chatons", ie brightly polished gold rings for setting the stones, which otherwise are just press-fitted into the brass baseplate and bars ('bridges'). Stones set in a chaton can be replaced (which is not the case otherwise), but this type of repair is very rare. Chatons are held in place with tiny steel screws and provide a pleasing colour contrast with rhodium plated or German silver main plate and bridges, dark red ruby bearings and blued screwheads. 
Gold alloys of the $14 \mathrm{ct}$ or $18 \mathrm{ct}$ type are perfectly suitable for fabricating the basic parts of a movement, ie baseplate and bars for particularly valuable watches. Even though the mechanical characteristics of those alloys are quite adequate for machining, rolling to the desired thickness is quite difficult, as gold tends to rebound and creep; such effects can only be partly compensated by heat treatments, milling and grinding. Among watchmakers, gold has a reputation of being a 'temperamental', 'nervous' metal.

Watch movement gears and non-lubricated scape wheels have often been made of gold, eg by the classical Danish watchmaker Urban Jürgensen for whom the preferred alloy was 9 to $10 \mathrm{ct}$; it is harder than brass and does not significantly wear in contact with the steel pinions and under the effect of the "hammering" by the anchor pallets. Craftsmen in the Vallée de la Sagne were even specialised in gold gears and gold screws in the 19th century, this is where Jürgensen bought those parts. The rationale was mostly aesthetics, as solid gold can be polished to a mirror finish much superior to what can be achieved by plating. The new coaxial escapement developed by George Daniels on the Isle on Man and commercially produced by Omega since 1999 started with a prototype scape wheel made of gold. And of course the dart at the upper end of the pallets fork is sometimes made of gold instead of stainless steel, again to avoid lubrication.

Hairsprings made of gold-copper (sometimes goldsilver) alloys with $75 \%$ to $87.5 \%$ Au were used by Breguet in clocks and also by the manufacturers of movements for high quality British watches of the 19th century, bearing famous names such as Edward J Dent and John Roger Arnold. Such hairsprings were strongly work-hardened by cold rolling; they did not corrode and were nonmagnetic, but they were temperature sensitive. They had to be combined with bimetallic, temperature compensated balance wheels. Pocket watch movements with a gold hairspring were actually imported from Le Locle and just cased in Britain. John Arnold, Thomas Mudge and Thomas Earnshaw as well as Ulysse Nardin in Le Locle used gold hairsprings in their famous marine chronometers. Gold was eventually replaced by Invar type nickel-iron alloys, after much experimenting with other exotic, nonmagnetic materials such as platinum and even glass. Elastic gold later found a small niche in the 'Palliney' suspension alloys, which were used to make the torsion spring in the now almost defunct electromechanical measuring instruments. They were tried for hairsprings in the forties, but could not compete with the much superior Invar type alloys.
Watch movements of the highest quality grade made by Lange \& Söhne in Glashütte near Dresden were routinely equipped with a gold anchor and a gold scape wheel (presumably, a $14 \mathrm{ct}$ alloy was used) well into the 20th century. A gold anchor and scape wheel provide perfect corrosion protection and are non-magnetic, but they do not make much sense mechanically, as they should be as light as possible. Gold plating the balance is current practice, but this is not the case with the anchor which nowadays is almost invariably made of steel.

A watch bearing alloy typically consisting of $37.5 \%$ $\mathrm{Au}, 27.1 \% \mathrm{Cu}, 22.9 \% \mathrm{Ag}$ and $12.5 \% \mathrm{Pd}$ was still quoted in the literature towards the end of the 19th century, but it could not compete against ruby watchstones. The latter were invented by the Genevaborn mathematician and astronomer Thomas Fatio in 1704 and came into routine use in English watch movements in the first third of the 18th century.

To the author's knowledge, the mainspring, the balance, the axles, the pinions and the winding/setting mechanism seem to be the only metal parts of a mechanical watch that have not at one time or another been made of a gold alloy. A watch fully made of gold alloys is a challenge still waiting for a skilful metallurgist cum watchmaker.

\section{REMARKABLE GOLD WATCHES}

Constant Girard-Perregaux, the founder of the present Girard-Perregaux company, was extremely fond of gold, his favourite being the $18 \mathrm{ct}$ pink gold (with $20.5 \%$ copper and $4.5 \%$ silver). He used it not only for the case, dial, hands and crown, but also for watch movement parts such as bars, balance wheel counter weights, non-lubricated pallets wheel and detent spring (he was using a variant of the detent or chronometer escapement). This gold alloy can be heat treated at 280 ${ }^{\circ} \mathrm{C}$ and hardens to $320 \mathrm{HV}$, which is close to the hardness of brass. Other manufacturers have used pink $14 \mathrm{ct}$ gold for the detent escapement parts.

After thirty years of experimenting, GirardPerregaux hit upon the design of his masterpiece around 1880. It was the "tourbillon sous trois ponts d'or" in which three identical, symmetrically placed bar shaped pink gold bridges support the tourbillon, the barrel and the concentric axles of the minute and hour hands. Only about thirty watches of this unique design were built in Girard-Perregaux lifetime. But the original pocket size model was recreated in 1982 and miniaturized to wristwatch size a few years ago; it has become the leading model of the collection. 
Frédéric Piguet in Le Brassus (a Swatch Group company in the Vallée de Joux specializing in fine mechanical movements), have a 9 line mechanical movement ('Calibre 21') with 18 ct gold bottomplate and bridges in their catalogue. This movement is particularly attractive when it is skeletonized in order to make it as transparent as possible. Jaeger-LeCoultre, in nearby Le Sentier, issued a special series of their famous 'Reverso' in 1991 to celebrate the 60th anniversary of this model. It had been originally designed for British Army officers in India, who often broke their watch crystal while playing polo. Flipping the case around in its sophisticated metal support solved that problem. The commemorative model had a pink $18 \mathrm{ct}$ gold case $(20.5 \%$ copper and $4.5 \%$ silver) and a 'gold movement', the baseplate and the four bars being made of $14 \mathrm{ct}$ gold.

The ultimate gold watch case was designed in the seventies by Hans Ulrich Klingenberg, founder of the Century Time Gems Company in Bienne (now in nearby Nidau). The case consisted of a standard fine gold bar (1 troy ounce 999.9 gold for the ladies model, 2 ounces for gentlemen). Of course it had to be machined to accommodate the movement and the winding stem, but this weight loss was compensated by the weight of the bezel and the attachments for the strap. There was no dial, but the bullion used was minted to a high gloss; the fineness indication and serial number being left unchanged in most models. The sapphire crystal was pressed against the gasket by the bezel, $18 \mathrm{ct}$ gold screws were used for assembly. A kind of bullion watch was also made by Corum in La Chaux-de-Fonds in the eighties, using brightly minted 15 gram gold bars for the watchface; 10,5 or even 2.5 gram bars were sufficient for the smaller ladies' models.

Another very direct way of showing off gold is the coin watch. This is a traditional item, as there is a gold doubloon watch dating back to 1820 in the Girard Perregaux collection in La Chaux-de-Fonds. However, the hollowed out coin just acted as an outer case for a tiny Lépine gold watch which can be freely taken out. The baseplate, the bars and the dial of this watch are all made of solid gold. Modern coin watches with an integrated movement were launched by Corum in La Chaux-de-Fonds in 1964 and are still made today. To this effect, a real gold coin is split and machined in order to accommodate a super slim quartz or mechanical movement. The American Double Eagle (\$20 for men) and the $\$ 10, \$ 5$ and $\$ 2.5$ Eagles for women are most popular, followed by the French Napoleon, the British Sovereign and others. Once it is provided with its movement and crown, the coin is set in a slender gold ring with discrete indexes and attachments for the strap. This ring also acts as a bezel for holding the sapphire crystal.

\section{GOLD PLATING}

It was already mentioned that leaf gilding and fire gilding have been used since the very beginning of clock and watchmaking. Those technologies were almost completely replaced by electroplating, which was invented in 1802 by Luigi Brugnatelli, a professor of chemistry at the university of Padua. Brugnatelli used an early version of Volta's pile, the very first battery. He succeeded as early as 1805 to gold plate silver coins, but it took 40 years to develop the process for industrial use. It was patented in 1842 by Henry Fox Talbot.

The watch industry is a big user of electroplated gold: cases, bracelets, hands, bezels, dials, crowns and pushers can be made of stainless steel (the $316 \mathrm{~L}$ variety is usually chosen), brass or even 'alloy' (a zinc alloy containing aluminium, copper and magnesium) and then gold-plated. The thickness of this plating varies tremendously (it is of course directly related to price), ranging from a 0.1 micron flash on gold coloured titanium nitride to anywhere between 3 and 15 micron electroplated $18 \mathrm{ct}$ gold.

As to movement components, brass baseplates and bridges are given a 3 to 5 micrometer gold plating on top of a 1 to 3 micrometer nickel base for corrosion protection and decoration (the alternatives are plain nickel for cheap watches, rhodium for expensive ones); this of course applies both to mechanical and electronic movements. Brass gears (almost invariably engaging a hardened steel pinion) are given a similar gold plating, but before cutting the teeth. Soft gold wears off onto the hardened steel and builds up a sticky black trace which can slow down or even stop the movement.

There is practically no more gold plating of brass and alloy cases in the Swiss watch industry, as such low end items are exclusively made in the Far East. But galvanic gold plating of high quality stainless steel watchcases still has its importance, even though yellow metal has recently fallen out of favour. Every plater has his own favourite recipes and procedures for achieving high gloss, low porosity gold coatings on stainless steel, but most galvanic baths are based on gold chloride, sodium hydrophosphate, sodium sulfite and potassium cyanide. Zinc and copper salts are added in order to obtain wear resistant, $18 \mathrm{ct}$ coatings. The temperature 
usually is between 50 and $80{ }^{\circ} \mathrm{C}$, the voltage is $1.5 \mathrm{~V}$ at low current densities. The positive electrode is made of platinum plated titanium.

A full cycle of 7 to 12 micrometer plating and rinsing of steel watchcases takes 3 to 4 hours. A 12 micrometer plating for example usually consists of three different coatings. The first 2 micrometers on the stainless steel substrate consist of very pure $23.5 \mathrm{ct}$ gold with cobalt. The main, 9 micrometer thick coating is 18 ct gold with zinc and copper, while the abrasion resistant top coating consists of high carat gold with nickel and indium. The composition is adjusted to match the colour of other visible watch parts, such as face, hands, crown and bracelet.

Thermally evaporated gold is found on the sapphire crystal of some high end watches in the form of discrete lines or patterns, which of course are only applied near the edge. More particularly, this kind of decoration is used by the Rado company. The entire crystal is sometimes given a warm tint by gold evaporation: dial and hands are then seen through a gold film. Furthermore, golden logos, indexes and numerals can be vacuum-evaporated on the inner surface of the crystal.

\section{GOLD IN QUARTZ WATCHES}

The electronics industry is the second largest user of gold (after the jewellery trade), as it consumes more than 200 tonnes of gold per year world-wide. The inert nature, high electrical conductivity and low contact resistance are the most appreciated properties of gold in electronic applications. The electronic components used in quartz watches are highly specialised, but they do not in principle differ from the ones used in other microelectronic applications. Thus, all quartz watches are equipped with a tuning-fork shaped quartz crystal generating the frequency of $32768 \mathrm{~Hz}$. The latter is divided down to $1 \mathrm{~Hz}$ by the CMOS integrated circuit (often a microprocessor) and is used to control either a step motor in analogue watches, or a liquid crystal display in the digital variety. The latter has no mechanically moving parts (aside from pushers needed to adjust the time and trigger special functions).

In analogue quartz watches, the step motor actuates the second hand, which transfers its motion via a gear train to the minute and hour hands. The basic construction of this type of watch is very similar to that of the mechanical watch, except that the power is provided by a silver oxide-zinc battery (or a small rotor-generator, a set of solar cells or a thermoelectric generator in conjunction with a super-cap or a rechargeable lithium ion battery); the regulating organs are of course replaced by the quartz crystal. The similarity even goes a step further in the high end chronographs, in which the timing functions are purely mechanical, but operate in conjunction with an analogue quartz movement for accurate timekeeping. The use of gold (mostly plated) in such watches is no different than in classical mechanical timepieces.

As mentioned above, gold finds many uses in the specifically electronic parts of quartz watches. As pure gold is ductile, soft and readily forms cold welds, gold and gold plated components can be joined by thermocompression bonding. The bonding wires connecting the silicon chip of the integrated circuit to the lead-frame are usually made of gold; only $10 \%$ of the ICs use aluminium or palladium bonding wires. Wire in the diameter range of 13-37 micrometers is used, the average being 25 micrometers; it is produced by standard multiple set drawing through diamond dies. Gold for this application is doped with traces of aluminium, beryllium and calcium, or more recently rare earth metals which are added to 99.999 gold to inhibit grain growth and recrystallization.

IC connectors consist of bronze electroplated with gold; 0.1 to $1 \%$ of $\mathrm{Ni}$ or $\mathrm{Co}$ are co-precipitated to increase the hardness from $60 \mathrm{HV}$ to $150 \mathrm{HV}$. The same applies to the contact lugs for the battery. Watch batteries of the silver oxide zinc type consist of a laminated nickel-steel-copper cover in contact with the zinc powder anode (with up to $1 \%$ mercury) and a steel bottom part filled with silver oxide acting as cathode. Both materials are pressed to porous, pill shaped bodies and impregnated with a potassium hydroxide electrolyte. The inside surface of the cover in contact with the zinc powder consists of copper for a high hydrogen overvoltage and minimum hydrogen gassing. In former days, the copper film was given a galvanically deposited, 0.2 to 0.4 micrometer thick gold flash in order to further suppress hydrogen generation at the zinc-copper interface. However, gold in watch battery covers became unnecessary in the eighties, as the hydrogen overpotential can be controlled by using very pure zinc, while the toxic mercury in the zinc anode is (at least partly) replaced by indium.

Printed circuit board (PCB) tracks are plated with gold to avoid corrosion of the underlying copper and to improve solderability. The quartz crystals generating the frequency of $32768 \mathrm{~Hz}$ also contain gold: the precious metal evaporated on both sides of the tuning-fork forms complex patterns of contacts and gold patches which 
lower the resonant frequency. The latter is automatically adjusted to the correct value by computer-controlled laser beam evaporation before encapsulation.

A really exotic use of gold in an electronic movement is found in the luxury quartz watches of Girard-Perregaux in La Chaux-de-Fonds, where the battery is hidden unter a corrosion proof solid gold cover - decorated with Geneva stripes, just like the gold plated baseplate.

\section{FUNCTIONAL GOLD}

The aesthetic and functional aspects of solid gold (and plated gold) are intertwined in all the watch parts reviewed so far. However, there are important applications where gold is used, even though it remains totally invisible. For example, gold has a purely functional role in the new, glossy black and very hard DLC coatings (diamond like carbon) on cases, bracelet links and dials. DLC is deposited on gold plated brass at $450{ }^{\circ} \mathrm{C}$; the galvanic gold coating acts as a diffusion barrier for the zinc in the brass. This technology can be combined with selective lift-off. For example, the numerals on a dial are generated by using the classical photolithographic technique. Copper is plated on the gold wherever it is not protected by the photoresist. After removal of the latter, the entire dial is coated with 1 micrometer of DLC. As this coating is porous, an acid treatment dissolves the copper under the DLC which is lifted off in the process. Gold numerals surrounded by black DLC are the end result.

Another functional use of gold is found in the brazing of stainless steel watchband components. A galvanic gold-nickel coating acts as a perfect, flux-free solder, ie a gold-nickel eutectic with a melting point of $950^{\circ} \mathrm{C}$. This eutectic flows into the recesses by capillarity, exposed parts of the surface have the colour of stainless steel. Gold-copper-tin and gold-tin eutectics were developed for brazing gold at temperatures as low as $280^{\circ} \mathrm{C}$.

\section{ACKNOWLEDGEMENTS}

The author thanks the following persons for their kind co-operation: Bruno Affolter (Succ. Marcel Robert, La Chaux-de-Fonds); Roland Aubert (Frédéric Piguet SA, Le Brassus); Jürg Brunner and Marc Gilgen (Century Time Gems Ltd., Nidau), Catherine Cardinal (Musée International d'Horlogerie, La Chaux-de-Fonds), Pierre-Olivier Chave (Precinox SA, La Chaux-deFonds); Yves Droz (Musée de la Montre, Villers-leLac), Benoit Conrath and Michel Parmigiani (PMAT, Fleurier); Anne Kretz and Jasmina Steele (Patek Philippe, Genève), Alain Munier (Varinor, Delémont); Jack Ogden (National Association of Goldsmiths, London); Simone Prévalet (Jaeger-LeCoultre SA, Le Sentier); Christian Raub (Schwäbisch-Gmünd); Claude Roulet (Corum, Ries Bannwart \& Co, La Chaux-de-Fonds); Paul Rüetschi (Grandevent), Sylvie Rumo and Willy Schweizer (Girard-Perregaux SA, La Chaux-de-Fonds), Peter Röthlisberger (MECO SA, Grenchen); Clayton O. Ruud (Pennsylvania State University); Willi Salathé (Swatch Group, Biel); Maurizio Schiavo (LASCOR SpA, Sesto Calende); Kurt Schindler (W. Blösch AG, Grenchen).

\section{ABOUT THE AUTHOR}

The author is a graduate of the Physical Chemistry Department of the Swiss Federal Institute of Technology $(\mathrm{ETH})$ in Zurich, Switzerland. He worked as a research metallurgist and materials scientist both in Switzerland and the United States. From 1972 to 1997 he was the science and technology editor of Neue Zürcher Zeitung, the leading daily newspaper in Switzerland. He is the author of numerous articles and two books on gold and watchmaking, respectively. $\mathrm{He}$ is currently active as a freelance science writer and book author. 